\title{
Vitamin D supplement use in care home residents in Northern Ireland
}

\author{
J. McMullan ${ }^{1}$, O. Feehan ${ }^{1}$, P.J. Magee ${ }^{1}$, L.K. Pourshahidi ${ }^{1}$, D.J. Armstrong ${ }^{1,2}$ and \\ E.M. McSorley ${ }^{1}$ \\ ${ }^{1}$ Nutrition Innovation Centre for Food \& Health (NICHE), Ulster University, Coleraine, UK and \\ ${ }^{2}$ Western Health and Social Care Trust, Londonderry, UK
}

Vitamin D is an essential micronutrient for health, playing a key role in calcium absorption and bone metabolism ${ }^{(1)}$. Vitamin D deficiency can result in bone loss and an increased risk of osteoporosis, falls and fractures which are common within the ageing individ$\mathrm{ual}^{(1)}$. Further benefits of vitamin D include its role in supporting the immune system ${ }^{(2)}$. Those residing in care homes are at greater risk of vitamin D deficiency owing to poor dietary intake and a lack of exposure to sunlight decreasing the cutaneous synthesis of vitamin $\mathrm{D}^{(3)}$. To ensure optimal status, vitamin $\mathrm{D}$ supplementation may be particularly important for care home residents. This study aimed to investigate vitamin D supplement usage in nursing home residents and explore its association with vitamin $\mathrm{D}$ status.

A total of 87 care home residents (aged $\geq 65$ years) from eight care homes across the Western Health and Social Care Trust, Northern Ireland, were selected as part of a larger observational study. Information on calcium/vitamin D supplement usage and history of osteoporosis was taken from the participants' medical records. Data on 25-hydroxyvitamin D (25(OH)D) concentrations were available in 69 of the participants and was compared between supplement and non-supplement users. Vitamin D status cut-offs were based on guidance from the National Institute for Health and Care Excellence (NICE): 25-hydroxyvitamin D (25(OH)D) concentrations $<25 \mathrm{nmol} / \mathrm{L}$ (deficient), $25-50 \mathrm{nmol} / \mathrm{L}$ (insufficient), and $\geq 50 \mathrm{nmol} / \mathrm{L}$ (sufficient).

Participants $(40.2 \%$ males and $59.8 \%$ females) had a mean \pm SD age of $83 \pm 8$ years and BMI of $27.9 \pm 7.4 \mathrm{~kg} / \mathrm{m} 2$. Of the $87 \mathrm{residents}$, $41(47.1 \%)$ were receiving vitamin D supplements. Mean $25(\mathrm{OH}) \mathrm{D}$ concentration of all participants was $49.52 \pm 35.58 \mathrm{nmol} / \mathrm{L}$. For residents taking supplemental vitamin D, 90.2\% were prescribed an $800 \mathrm{IU}$ dose of vitamin D and $4.9 \%$ were prescribed a $400 \mathrm{IU}$ dose. Vitamin D supplement users had a significantly higher vitamin D status compared to non-users $(73.23 \pm 26.20 \mathrm{nmol} / \mathrm{L}$ vs $27.78 \pm 28.56 \mathrm{nmol} / \mathrm{L}$ respectively, $\mathrm{p} \leq 0.0001) .65 .9 \%$ of those taking a supplement had sufficient $25(\mathrm{OH}) \mathrm{D}$ concentrations, as compared with only $13 \%$ of non-supplement users. Likewise, $50 \%$ of participants not taking a supplement had deficient $25(\mathrm{OH}) \mathrm{D}$ concentrations, compared with only $2.4 \%$ of those prescribed vitamin D. A previous diagnosis of osteoporosis was observed in $51.2 \%$ of supplement users. In total, $57.1 \%$ of residents diagnosed with osteoporosis were co-prescribed bisphosphonates with vitamin D supplementation indicating ongoing management of osteoporosis, albeit some $25.0 \%$ diagnosed with osteoporosis were on no form of vitamin D supplementation.

Residents on supplementation had a significantly higher vitamin D status and were more likely to be sufficient compared to nonsupplemented residents. Given the high prevalence of vitamin D deficiency in non-supplement users there is a need for public health guidelines to include specific recommendations for older adults in residential care in terms of vitamin D supplementation for the prevention of deficiency.

\section{References}

1. Laird E, Ward M, McSorley E, et al. (2010) Nutrients 2, 693-724.

2. Laird E, McNulty H, Ward M, et al. (2014) J Clin Endocrinol Metab 99, 1808-1815.

3. Meehan M \& Penckofer S (2014) J Aging Gerontol 2, 60-71. 